TITLE:

\title{
Effects of embryonic responses to clutch mates on egg hatching patterns of Pentatomidae (Heteroptera)
}

\author{
$\operatorname{AUTHOR(S):~}$
}

Endo, Jun; Numata, Hideharu

\section{CITATION:}

Endo, Jun ...[et al]. Effects of embryonic responses to clutch mates on egg hatching patterns of Pentatomidae (Heteroptera). Physiological Entomology 2017, 42(4): 412-417

\section{ISSUE DATE:}

2017-12

URL:

http://hdl.handle.net/2433/229666

\section{RIGHT:}

This is the accepted version of the following article: [Endo, J. and Numata, H. (2017), Effects of embryonic responses to clutch mates on egg hatching patterns of Pentatomidae (Heteroptera). Physiological Entomology, 42: 412-417], which has been published in final form at https://doi.org/10.1111/phen.12219. This article may be used for non-commercial purposes in accordance with Wiley Terms and Conditions for Self-Archiving.; The full-text file will be made open to the public on 6 NOV 2018 in accordance with publisher's 'Terms and Conditions for Self-Archiving'.; この論文は出版社版て ありません。引用の際には出版社版をじ確認ご利用ください。; This is not the published version. Please cite only the published version. 
Effects of embryonic responses to clutch mates on egg hatching patterns of Pentatomidae (Heteroptera)

Running title: Egg hatching patterns of Pentatomidae

JUN ENDO and HIDEHARU NUMATA

Department of Zoology, Graduate School of Science, Kyoto University, Kyoto, Japan

Correspondence: Hideharu Numata, Graduate School of Science, Kyoto University, Kyoto 606-8502, Japan. Tel.: +81-75-753-4073; e-mail: numata@ethol.zool.kyoto-u.ac.jp, 
Abstract. Stink bugs and shield bugs of Pentatomidae (Heteroptera) generally produce a clutch of densely deposited eggs. In a few species of this family, it is known that embryos hatch in response to some kind of cues associated with the preceding hatching to synchronize egg hatching with clutch mates. For a family-wide understanding of the extent to which the hatching response to clutch mates accelerate hatching within egg clutches, in the present study, the hatching patterns in intact egg clutches and eggs individually detached from egg clutches were compared in eight species among different genera. In Halyomorpha halys, hatching was significantly and highly synchronized by the effect of the hatching response: When eggs were not attached to each other, the hatching rate was only $3.8 \%$ at $15 \mathrm{~min}$ and exceeded $95 \%$ at $200 \mathrm{~min}$. In contrast, when eggs were attached to each other, the hatching rate reached more than $95 \%$ at 15 min. Hatching was also significantly synchronized by the hatching response in Nezara viridula (which showed relatively high hatching synchronization) and in Piezodorus hybneri and Plautia stali (both of which showed milder hatching synchronization). Synchronization of hatching was not found to be promoted by a hatching response in Aelia fieberi, Dolycoris baccarum, Eurydema rugosum, or Palomena angulosa. These findings revealed that the hatching response varies depending on the species in Pentatomidae, with a wide spectrum of effects on the hatching patterns of the egg clutches.

Key words. Clutch mate $\cdot$ egg clutch $\cdot$ Halyomorpha halys $\cdot$ interspecific variation $\cdot$ Nezara viridula $\cdot$ Pentatomidae $\cdot$ sibling association $\cdot$ synchronized hatching 


\section{Introduction}

Embryos of many egg-laying animals control the timing of hatching to adapt to various environmental or ecological contexts. Particularly in species that produce egg clutches, an important context is the social association that involves siblings in the same clutch. Increasing empirical evidence has shown that these species have, in some cases, evolved to synchronize egg hatching within a clutch to profit from the sibling associations (Warkentin \& Caldwell, 2009; Warkentin, 2011). Among insect species that produce egg clutches, newly hatched larvae of the large white butterfly, Pieris brassicae (Lepidoptera: Pieridae), assist hatching of the adjacent eggs by biting and tearing the egg chorions. The resulting synchronized hatching enables ensuing aggregation and mass migration to the feeding site (Long, 1955). Hatching of the desert locust, Schistocerca gregaria (Orthoptera: Acrididae), occurs in response to some mechanical stimuli generated by earlier hatching. Potentially, this hatching response serves to avoid cannibalism because hatchlings are often attacked by older siblings when their hatching is delayed for a long time (Nishide \& Tanaka, 2016).

In Pentatomidae (Heteroptera), some species are known to show an egg hatching response to clutch mates. A female of this group in general glues her eggs together on one place on a plant so that the eggs form a dense mass. After oviposition, females do not display egg protection behaviour, and thus cannot regulate the timing of hatching of the offspring behaviourally, in contrast to their sub-social relatives of Cydnidae and Parastrachiidae (Mukai et al., 2012, 2014). In one species of Pentatomidae, Eurydema rugosum, when hatching patterns were compared between intact egg clutches and eggs individually detached from egg clutches, hatching proceeded more synchronously when eggs remained attached to each other (Morimoto, 1965). From these results, Morimoto (1965) suggested that an intact egg clutch shows a synchronized hatching pattern because some kind of cue(s) associated with earlier hatching stimulate successive hatchings. Similarly, Lockwood \& Story (1985) showed in 
Nezara viridula that two single detached eggs required more time for hatching than two attached eggs, and suggested the presence of a hatching response to clutch mates. In another species, Halyomorpha halys, a synchronized hatching pattern has been noted only by observation of intact egg clutches (Taylor, 2016). In the latter two species, however, the extent to which hatching of an egg clutch is accelerated through the hatching response has not been elucidated, and thus it is unclear whether the effect is similar or different among species within Pentatomidae.

To clarify the commonality and interspecific variation of such a response among pentatomids, we observed hatching of intact egg clutches and eggs individually detached from egg clutches in eight species among different genera, including the three species mentioned above: Aelia fieberi, Dolycoris baccarum, E. rugosum, $H$. halys, N. viridula, Palomena angulosa, Piezodorus hybneri, and Plautia stali. We expect that, in Pentatomidae, the synchronized hatching mediated by a hatching response to clutch mates is an adaptation of embryos to some social contexts among siblings in their early developmental stages. The present study may potentially unveil complexity underlying these social contexts.

\section{Materials and methods}

Insect rearing and preparation of egg clutches

Adults of A. fieberi, D. baccarum, E. rugosum, H. halys, N. viridula, P. angulosa, $P$. hybneri, and P. stali were collected from the field in Kyoto, Osaka, and Hyogo Prefectures, Japan, in 2014-2016 to obtain egg clutches. These adults were provided with water and oviposition sites made of drawing paper in plastic cases under LD $16: 8 \mathrm{~h}$ at $25^{\circ} \mathrm{C}$. Raw seeds of peanut, Arachis hypogaea, and dried seeds of soybean, Glycine max, were fed to D. baccarum, H. halys, $N$. viridula, P. angulosa, P. hybneri, and P. stali; dried seeds of barley, 
Hordeum vulgare, and supplementary dried seeds of a wild rye, Elymus tsukushiensis, to A. fieberi; and dried seeds of a mustard, Brassica juncea, to E. rugosum. Egg clutches laid within $24 \mathrm{~h}$ were cut out with their ovipositional substrates, and then kept in a plastic container at $25^{\circ} \mathrm{C}$ and $80 \%$ or higher relative humidity until they were used for experiments described below. Although Kiritani \& Hokyo (1965) stated that, in Pentatomidae, the clutch size (i.e., the number of eggs in a single egg clutch) is largely fixed according to the species, in our laboratory-reared insects, egg clutches with a wide range of sizes were observed for each species. To minimize possible variation in results originating from this size variation, egg clutches used for this study were limited to a particular range of clutch size that included frequently observed sizes: $12 \pm 2$ for $A$. fieberi and E. rugosum; $14 \pm 2$ for $P$. angulosa and $P$. stali; $28 \pm 4$ for D. baccarum, H. halys, and P. hybneri; and $84 \pm 13$ for $N$. viridula.

\section{Recording of hatching patterns}

The following preparations for observation were conducted within $60 \mathrm{~h}$ before the first hatching of egg clutches. Intact egg clutches were fixed with a piece of double-stick tape on the bottom of a clear plastic case $(36 \times 36 \mathrm{~mm}, 14 \mathrm{~mm}$ height $)$, together with wet cotton to prevent desiccation. Detachment of individual eggs from egg clutches was carried out with a razor blade and forceps under a binocular stereomicroscope (S8 APO, Leica Microsystems, Wetzlar, Germany). However, this method alone was not successful for egg clutches of $D$. baccarum, $N$. viridula, or $P$. hybneri due to the combinations of their fragile chorions and tight attachment between eggs. For these three species, the attachment between eggs was loosened by moistening beforehand on wet cotton for 10-30 minutes. Each of the detached eggs was then separately attached to a piece of drawing paper $(5 \times 8 \mathrm{~mm})$ using starch glue, and individually fixed using a piece of double-stick tape in a well $(9.85 \mathrm{~mm}$ diameter, 17.50 mm depth) of a flat-bottom, 48-well culture plate (AGC Techno Glass, Shizuoka, Japan), at 
the end of a plastic column ( $5 \mathrm{~mm}$ diameter, $10 \mathrm{~mm}$ height $)$ that had been attached at the centre of the bottom of the well. To prevent desiccation of the egg, $200 \mu$ water was poured into the well. The above detaching procedures seemed to have little or no effect on the hatching of embryos in all the species examined, because hatching rates were not significantly different between intact egg clutches and eggs individually detached from egg clutches (Mann-Whitney $U$ test, $P>0.1$ ).

Subsequently, temporal patterns of hatching were recorded for intact egg clutches and eggs individually detached from egg clutches using time-lapse photography with a digital camera (CX6, Ricoh, Tokyo, Japan and P310, Nikon, Tokyo, Japan) from the top view at $25^{\circ} \mathrm{C}$ under constant light (photon flux density of approximately $3.6 \mu \mathrm{mol} \mathrm{m}{ }^{-2} \mathrm{~s}^{-1}$, FL15D, Toshiba, Tokyo, Japan). In intact egg clutches, hatching of an egg was sometimes concealed by nymphs that had previously hatched and were covering the top surface of the egg. Thus, the hatching time of each egg was defined as the time when its hatchling was first identified in photographs. The number of hatchings was determined every 5 min for $6 \mathrm{~h}$ after the first hatching by analyzing the photographs taken at intervals of $1 \mathrm{~min}$ for intact egg clutches and 5 min for eggs individually detached from egg clutches. Both in intact egg clutches and eggs individually detached from egg clutches, hatching was usually completed within $6 \mathrm{~h}$ in all the species examined. Egg clutches in which $10 \%$ or more eggs did not hatch within this period were excluded from analyses. To determine temporal patterns of hatching, cumulative hatching rates were calculated as proportions relative to the total number of hatchings at $6 \mathrm{~h}$.

\section{Statistical analyses}

To examine differences in temporal hatching patterns between intact egg clutches and eggs individually detached from egg clutches, time-treatment interaction effects were analysed by two-way repeated measures ANOVA. Eight time points of the hatching patterns 
were used for the analyses. The initial time point was determined as $5 \mathrm{~min}$ and the final point was selected for each species so that all the interval between the points become equal and mean cumulative hatching rates of both intact clutches and eggs individually detached from clutches exceeded $90 \%$ between the seventh and eighth points (145 min for P. angulosa, $P$. hybneri, and P. stali, $180 \mathrm{~min}$ for A. fieberi and E. rugosum, and $215 \mathrm{~min}$ for D. baccarum, $H$. halys, and $N$. viridula. The hatching rates were arcsine transformed for variance stabilization. Greenhouse-Geisser corrections were used to calculate $P$-values because sphericity assumptions for the ANOVA tests were violated (Greenhouse \& Geisser, 1959).

To examine whether the second hatching occurs predominantly in an egg adjacent to the first hatching egg, the observed frequency of the second hatching occurring next to the first hatching egg was compared with the expected frequency when the second hatching was assumed to occur randomly within an egg clutch, using a one-tailed binomial test. Because hatching was recorded at 1-min intervals, sometimes both an egg next to the first hatching egg and another egg hatched within the same interval. In these cases, all possibilities were taken into account to calculate $P$-values.

\section{Results}

Effect of hatching response

Temporal patterns of hatching were compared between intact egg clutches and eggs individually detached from egg clutches for eight species in Pentatomidae to test the effect of hatching response to clutch mates on the hatching patterns (Fig. 1). Although the duration of the egg period and the total number of hatchings may also influence the hatching pattern, these parameters were not significantly different between intact egg clutches and eggs individually detached from egg clutches (Table 1). The hatching patterns significantly 
differed depending on the presence or absence of the contact between eggs for A. fieberi, $H$. halys, N. viridula, P. hybneri, and P. stali, but not for D. baccarum, E. rugosum, or $P$. angulosa (Fig. 1). Intact egg clutches of $A$. fieberi hatched less synchronously than eggs individually detached from egg clutches during the latter half of the hatching progress (Fig. 1A), although the reason for this is unclear. In H. halys, N. viridula, P. hybneri, and P. stali, hatching proceeded more synchronously throughout the hatching progress when eggs were attached to each other (Fig. 1D, E, G, H). Accordingly, we concluded that a hatching response to clutch mates existed in these four species.

In particular, the temporal patterns of hatching showed a sharp contrast between intact egg clutches and eggs individually detached from egg clutches in $H$. halys. Hatching proceeded gradually when eggs were not attached to each other: Within the first $15 \mathrm{~min}$, only a small proportion of eggs in an egg clutches (median, 3.8\%, interquartile range [IQR], 3.7-7.4\%) started hatching, and the hatching rate exceeded $95 \%$ at 200 min (median, $96.3 \%$, IQR, 86.8-100.0\%; Fig. 1D). However, hatching spread rapidly when eggs were attached to each other (Fig. 2): 15 min after the first hatching, the hatching rate reached more than $95 \%$ (median, 96.4\%, IQR, 96.3-100\%; Fig. 1D). Compared with H. halys, hatching was less accelerated in $N$. viridula, and far less accelerated in P. hybneri and P. stali via the attachment between eggs (Fig. 1D, E, G, H).

\section{Spatial patterns of hatching}

In intact egg clutches of some species, hatching seemed to spread from hatched eggs toward adjacent ones successively. To assess this spatial pattern of hatching, we examined whether a second hatching was more likely to occur at an egg adjacent to the first hatching egg than would be predicted by random hatching (Table 2). The results showed that such a tendency was evident in N. viridula, P. hybneri, and P. stali, uncertain in H. halys, and 
improbable in A. fieberi, D. baccarum, E. rugosum, and P. angulosa. Hatching of $H$. halys spread as follows: After the first hatching (Fig. 2A), hatching of not only the adjacent eggs but many peripheral eggs followed immediately and almost simultaneously (Fig. 2B). Then, eggs that were positioned far from the earliest-hatching one in the egg clutch followed with a slight delay (Fig. 2C).

\section{Discussion}

Interspecific variations in temporal hatching patterns

In a few species of Pentatomidae, a hatching response to clutch mates is known to be an important factor that affects the temporal pattern of hatching within an egg clutche (Morimoto, 1965; Lockwood \& Story, 1985). In the present study, we found that the hatching response varies depending on the species in Pentatomidae, with a wide spectrum of effects on the hatching patterns. Among the eight species examined, the hatching response clearly occurred in $H$. halys, $N$. viridula, $P$. hybneri, and $P$. stali, resulting in more synchronized egg hatching. In $H$. halys, remarkably, the hatching response greatly accelerated the hatching and consequently led to highly synchronized patterns. However, no evidence of such a response was found in A. fieberi, D. baccarum, E. rugosum, or P. angulosa. Our findings in E. rugosum contradict those of Morimoto (1965) that hatching of intact egg clutches proceeds faster than hatching of eggs individually detached from egg clutches, although the observation temperature that Morimoto used $\left(27^{\circ} \mathrm{C}\right)$ was different from ours $\left(25^{\circ} \mathrm{C}\right)$. We cannot exclude the possibility that a hatching response exists in E. rugosum also, but its effect may be observable only in particular conditions or differ substantially among individuals in the species.

Through the more synchronized hatching resulting from the hatching response to 
clutch mates, embryos or nymphs of Pentatomidae presumably adapt to some social context among siblings. The interspecifically different hatching patterns indicate that the social context varies greatly among the species in Pentatomidae. Especially, the social context of $H$. halys seems to be considerably different from that of the other species, and forces the embryos to hatch within a very short period. To suggest directions for further studies, we discuss the possible mechanisms producing the interspecifically different hatching patterns and the adaptive functions of synchronized hatching in Pentatomidae.

\section{Mechanisms of hatching stimulation}

In N. viridula, $P$. hybneri, and P. stali, hatching spread from the first egg toward the adjacent ones. Although such a tendency was not as clear in $H$. halys, eggs near the first hatching were likely to hatch earlier than distant ones. Thus, these four species that possess the hatching response showed some kind of spreading hatching patterns. On the other hand, we could not observe such hatching patterns for the other four species in which the hatching response was not detected (i.e., A. fieberi, D. baccarum, E. rugosum, and P. angulosa). Accordingly, we consider that the spreading hatching patterns are associated with a hatching response. To produce such hatching patterns, the most simply understood mechanism would be a hatching response to a cue associated with the preceding hatching, supporting the speculation by Morimoto (1965) and Lockwood \& Story (1985). In egg clutches of Heteroptera, there are some examples of embryonic responses to physical cues or signals at hatching. In some sub-social bugs of Cydnidae and Parastrachiidae, synchronized hatching is due to a rapid response of embryos to a maternally provided vibration signal (Mukai et al., 2012, 2014). In the giant water bug, Kirkaldyia (= Lethocerus) deyrolli (Belostomatidae), the mechanical shock of embryonic moulting is presumed to stimulate moulting of adjacent embryos (Ohba, 2002). During the hatching process of individual eggs in Pentatomidae, an 
embryo ruptures the operculum, and wriggles out of the egg chorion. After hatching, the first-instar nymph steps on its clutch mates by walking over the egg clutche. These physical movements probably produce some distinctive vibrations or pressures that are transmitted to other embryos, and thus potentially stimulate their hatching, as previously speculated (Morimoto, 1965; Lockwood \& Story, 1985).

We can explain the proximate causes of the interspecific variation in the effectiveness of the hatching responses by differences in embryos' responsiveness to a cue or differences in the intensity and timing of generation of the cue. Alternatively, differences in the egg clutch structure may partially explain the variation as follows: Hatching was more accelerated in $N$. viridula than in P. hybneri despite the fact that the processes of hatching spread were similar between them. In both species, eggs are arranged in such a manner that every three adjacent eggs form an equilateral triangle (i.e., hexagonal or triangular lattice). However, eggs of $N$. viridula have contact with a larger number of sibling eggs than those of P. hybneri on average, because the eggs are lined in more rows in the former species (Fig. 2E, G). Thus in N. viridula, hatching cues may be transmitted to more eggs simultaneously. Compared with the hatching of $N$. viridula, P. hybneri, and P. stali, hatching of $H$. halys showed the unique features that the first hatching was soon followed by hatching of many nearby eggs, and the nearest eggs were often not the fastest followers. These observations indicate that a cue reaches distant eggs in $H$. halys but only adjacent eggs in the other species.

\section{Adaptive functions of synchronized hatching}

It is likely that pentatomids adapt to different social contexts among siblings through species-specific synchronized hatching patterns during the early developmental stages. Based on several types of early sibling associations known in this family, several hypotheses to explain the interspecifically different adaptations are conceivable as follows: 
In this family, newly hatched nymphs form a tight nymphal aggregation persisting for a few days on or around a natal egg clutch (Kiritani, 1964). This aggregation is important for the nymphs' growth and survival (Kiritani, 1964; Kiritani \& Kimura, 1966; Nielsen et al., 2008). Moreover, this aggregation also helps them to cope with low temperature, desiccation, predators, and drop out from plants (Lockwood \& Story, 1986). Synchronized hatching can profit hatchlings through accelerating formation of the aggregation, as Morimoto (1965) predicted. Thus, if hatchlings need to aggregate more rapidly, more synchronized hatching is favoured.

Just after hatching, nymphs of Pentatomidae roam on the egg clutch for a certain period, and this behaviour is known to be associated with acquisition of symbiont resources (Abe et al., 1995), which are contained in maternal secretions smeared over the egg surface (e.g., H. halys, Taylor et al., 2014; N. viridula, Prado et al., 2006). A necessity for external digestion has been proposed for the acquisition process, and cooperative behaviour seems to help it (Taylor, 2016). Conversely, competition can occur between hatchlings if the symbiont resource is limited. In both circumstances, it is advantageous to hatch without delay after hatching of other clutch mates.

In insects whose hatchlings cannibalize intra-clutch eggs, when hatching occurs more synchronously, fewer eggs are eaten by the previously hatched nymphs (Fox, 1975; Crespi, 1992). Synchronized hatching might function to avoid cannibalism if the hatchlings are egg-cannibalistic. Such cannibalism is known in multiple Pentatomomorpha families, such as Lygaeidae (Root \& Chaplin, 1976) and Cydnidae (Nakahira, 1994; Kudo \& Nakahira, 2004). In Pentatomidae, egg cannibalism by older nymphs and adults has been reported (Kiritani et al 1966; Stam, 1987; Iverson et al., 2016). However, it had long been believed that first-instar nymphs of this family do not feed at all (e.g., H. halys, Lee et al., 2013; N. viridula, Kiritani, 1964; Lockwood \& Story, 1986). Although a recent study provided evidence of plant feeding by $N$. viridula as determined by detection of a marker bacteria that 
had infected to a food source (Esquivel \& Medrano, 2014), there are no reports of egg cannibalism by hatchlings in this family. However, we observed preliminarily in some pentatomid species, including $H$. halys, that hatchlings suck unfertilized eggs or unhatched fertilized eggs, if any, in the natal egg clutch. It will be important to examine the variation of this cannibalistic tendency along with its relation to species-specific hatching patterns in Pentatomidae.

In conclusion, our findings imply that there are interspecifically different physiological, environmental, or social constraints in the early lives of Pentatomidae. Together with functional studies of the different synchronized hatching patterns, the present study will contribute to the understanding of these constraints.

\section{Acknowledgements}

We thank Kazuhiko Kuge and Masaho Haikata for assistance in collecting insects. We are also grateful to Yoshito Suzuki and Akira Mori for advice and Elizabeth Nakajima for linguistic corrections.

\section{References}

Abe, Y., Mishiro, K. \& Takanashi, M. (1995) Symbiont of brown-winged green bug, Plautia stali Scott. Japanese Journal of Applied Entomology and Zoology, 39, 109-115 [in Japanese with English abstract].

Crespi, B.J. (1992) Cannibalism and trophic eggs in subsocial and eusocial insects. Cannibalism: ecology and evolution among diverse taxa (ed. by M. A. Elgar and B. J. Crespi), pp. 176-213. Oxford University Press, Oxford.

Esquivel, J.F. \& Medrano, E.G. (2014) Ingestion of a marked bacterial pathogen of cotton 
conclusively demonstrates feeding by first instar southern green stink bug (Hemiptera: Pentatomidae). Environmental Entomology, 43, 110-115.

Fox, L.R. (1975) Cannibalism in natural populations. Annual Review of Ecology and Systematics, 6, 87-106.

Greenhouse, S.W. \& Geisser, S. (1959) On methods in the analysis of profile data. Psychometrika, 24, 95-112.

Iverson, J.M., Cira, T.M., Burkness, E.C. \& Hutchison, W. (2016) Cannibalistic oophagy in Halyomorpha halys (Hemiptera: Pentatomidae) laboratory colonies. Journal of Entomological Science, 51, 122-128.

Kiritani, K. (1964) The effect of colony size upon the survival of larvae of the southern green stink bug, Nezara viridula. Japanese Journal of Applied Entomology and Zoology, 8 , 45-53.

Kiritani, K. \& Hokyo, N. (1965) Variation of egg mass size in relation to the oviposition pattern in Pentatomidae. Kontyû, 33, 427-433.

Kiritani, K. \& Kimura, K. (1966) A study on the nymphal aggregation of the cabbage stink bug, Eurydema rugosum Motschulsky (Heteroptera: Pentatomidae). Applied Entomology and Zoology, 1, 21-28.

Kiritani, K., Nakasuji, F. \& Hokyo, N. (1966) The survival rate of eggs and larvae in relation to group size in the southern green stink bug, Nezara viridula L. Japanese Journal of Applied Entomology and Zoology, 10, 205-211 [in Japanese with English abstract].

Kudo, S. \& Nakahira, T. (2004) Effects of trophic-eggs on offspring performance and rivalry in a sub-social bug. Oikos, 107, 28-35.

Lee, D.H., Short, B.D., Joseph, S.V., Bergh, J.C. \& Leskey, T.C. (2013) Review of the biology, ecology, and management of Halyomorpha halys (Hemiptera: Pentatomidae) in China, Japan, and the Republic of Korea. Environmental Entomology, 42, 627-641.

Lockwood, J.A. \& Story, R.N. (1985) Photic, thermic, and sibling influences on the hatching 
rhythm of the southern green stink bug, Nezara viridula (L.). Environmental Entomology, $14,562-567$.

Lockwood, J.A. \& Story, R.N. (1986) Adaptive functions of nymphal aggregation in the southern green stink bug, Nezara viridula (L.) (Hemiptera: Pentatomidae). Environmental Entomology, 15, 739-749.

Long, D.B. (1955) Observations on sub-social behaviour in two species of lepidopterous larvae, Pieris brassicae L. and Plusia gamma L. Transactions of the Royal Entomological Society of London, 106, 421-437.

Morimoto, N. (1965) Synchronization of hatching in an egg mass of the cabbage stink bug, Eurydema rugosa. Japanese Journal of Applied Entomology and Zoology, 9, 125-126 [in Japanese].

Mukai, H., Hironaka, M., Tojo, S. \& Nomakuchi, S. (2012) Maternal vibration induces synchronous hatching in a subsocial burrower bug. Animal Behaviour, 84, 1443-1448.

Mukai, H., Hironaka, M., Tojo, S. \& Nomakuchi, S. (2014) Maternal vibration: an important cue for embryo hatching in a subsocial shield bug. PLOS ONE, 9, e87932.

Nakahira, T. (1994) Production of trophic eggs in the subsocial burrower bug Admerus triguttulus. Naturwissenschaften 81, 413-414.

Nielsen, A.L. Hamilton, G.C. \& Matadha, D. (2008) Developmental rate estimation and life table analysis for Halyomorpha halys (Hemiptera: Pentatomidae). Environmental Entomology, 37, 348-355.

Nishide, Y. \& Tanaka, S. (2016) Desert locust, Schistocerca gregaria, eggs hatch in synchrony in a mass but not when separated. Behavioral Ecology and Sociobiology, 70, 1507-1515.

Ohba, S. (2002) Synchronized mechanism and its meaning in the egg hatching of the giant water bug, Lethocerus deyrolli (Heteroptera: Belostomatidae). Japanese Journal of Entomology (New Series), 5, 157-164 [in Japanese with English abstract].

Prado, S.S., Rubinoff, D. \& Almeida, R.P. (2006) Vertical transmission of a pentatomid 
caeca-associated symbiont. Annals of the Entomological Society of America, 99, 577-585.

Root, R.B. \& Chaplin, S.J. (1976) The life-styles of tropical milkweed bugs, Oncopeltus (Hemiptera: Lygaeidae) utilizing the same hosts. Ecology, 57, 132-140.

Stam, P., Newsom, L. \& Lambremont, E. (1987) Predation and food as factors affecting survival of Nezara viridula (L.) (Hemiptera: Pentatomidae) in a soybean ecosystem. Environmental Entomology, 16, 1211-1216.

Taylor, C.M. (2016) Understanding the relationship between the brown marmorated stink bug, Halyomorpha halys (Stål), and its symbiont, Pantoea carbekii, with implications for stink bug management. PhD dissertation, University of Maryland, College Park, Maryland.

Taylor, C.M., Coffey, P.L., DeLay, B.D. \& Dively, G.P. (2014) The importance of gut symbionts in the development of the brown marmorated stink bug, Halyomorpha halys (Stål). PLoS ONE, 9, e90312.

Warkentin, K.M. (2011) Environmentally cued hatching across taxa: embryos respond to risk and opportunity. Integrative and Comparative Biology, 51, 14-25.

Warkentin, K.M. \& Caldwell, M.S. (2009) Assessing risk: embryos, information, and escape hatching. Cognitive ecology II: the evolutionary ecology of information processing and decision-making (ed. by R. Dukas and J. M. Ratcliffe), pp. 177-200. University of Chicago Press, Chicago, Illinois. 
Table 1. Comparison of various parameters between intact egg clutches and eggs individually detached from egg clutches of eight species in Pentatomidae at $25^{\circ} \mathrm{C}$.

\begin{tabular}{|c|c|c|c|c|c|c|c|c|}
\hline \multirow[t]{2}{*}{ Species } & \multicolumn{2}{|l|}{$n$} & \multicolumn{2}{|l|}{ Clutch size $^{\mathrm{a}}$} & \multicolumn{2}{|c|}{ Egg period $(\text { day })^{\mathrm{a}}$} & \multicolumn{2}{|c|}{ No. of hatching eggs in $6 \mathrm{~h}^{2}$} \\
\hline & Intact & Detached & Intact & Detached & Intact & Detached & Intact & Detached \\
\hline Aelia fieberi & 15 & 20 & 12 [11-12] & $12[11-13]$ & $5[5-6]$ & $5[4-6]$ & 12 [11-12] & 12 [11-13] \\
\hline Dolycoris baccarum & 16 & 13 & 28 [26-31] & 28 [25-29] & $5[4-5]$ & $5[4-6]$ & 27.5 [24-29] & 27 [25-29] \\
\hline Eurydema rugosum & 18 & 19 & $12[11-12]$ & $12[11-12]$ & $6[5-6]$ & $6[5-6]$ & $12[11-12]$ & 12 [11-12] \\
\hline Halyomorpha halys & 15 & 15 & $28[27-28]$ & $28[26-28]$ & $5[5-5]$ & $5[5-6]$ & 28 [27-28] & 27 [25-28] \\
\hline Nezara viridula & 13 & 10 & 83 [72-96] & 84.5 [75-96] & $6[5-7]$ & $6[5-6]$ & 81 [69-94] & 80.5 [71-93] \\
\hline Palomena angulosa & 12 & 9 & $14[12-14]$ & 14 [14-14] & $6[5-7]$ & $6[5-6]$ & 14 [12-14] & 14 [13-14] \\
\hline Piezodorus hybneri & 20 & 15 & $27.5[24-32]$ & 28 [25-32] & $5[4-6]$ & $5[4-5]$ & 27 [23-32] & $28[24-32]$ \\
\hline Plautia stali & 22 & 11 & 14 [14-14] & 14 [14-15] & $4[4-5]$ & $4[4-5]$ & 14 [13-14] & 14 [13-15] \\
\hline
\end{tabular}

${ }^{a}$ The values are not significantly different between intact egg clutches and eggs individually detached from egg clutches (Mann-Whitney $U$ test, $\mathrm{P}>0.05$ ). Data are shown as median and minimum/maximum values. 
Table 2. Comparison between observed frequencies of the second hatching occurring in an egg adjacent to the first hatching egg of an intact egg clutches and those expected by random hatching in eight species in Pentatomidae.

\begin{tabular}{lllll}
\hline Species & $n$ & Observed frequency & Expected frequency & $P^{\mathrm{a}}$ \\
\hline Aelia fieberi & 15 & 0.27 & 0.32 & 0.76 \\
Dolycoris baccarum & 16 & $0.06-0.13^{\mathrm{b}}$ & 0.16 & $0.74-0.94^{\mathrm{b}}$ \\
Eurydema rugosum & 18 & 0.39 & 0.32 & 0.33 \\
Halyomorpha halys & 15 & $0.13-0.27^{\mathrm{b}}$ & 0.12 & $0.096-0.55^{\mathrm{b}}$ \\
Nezara viridula & 13 & $0.69-0.77^{\mathrm{b}}$ & 0.07 & $<0.001$ \\
Palomena angulosa & 12 & 0.42 & 0.29 & 0.26 \\
Piezodorus hybneri & 20 & 0.35 & 0.14 & 0.02 \\
Plautia stali & 22 & 0.45 & 0.22 & 0.01 \\
\hline
\end{tabular}

${ }^{\text {a }} P$-values were calculated using one-tailed binomial tests.

${ }^{\mathrm{b}}$ The values are shown as possible ranges because the second hatching could not be exactly determined in some of the egg clutches. 
— Intact egg mass — Detached egg mass
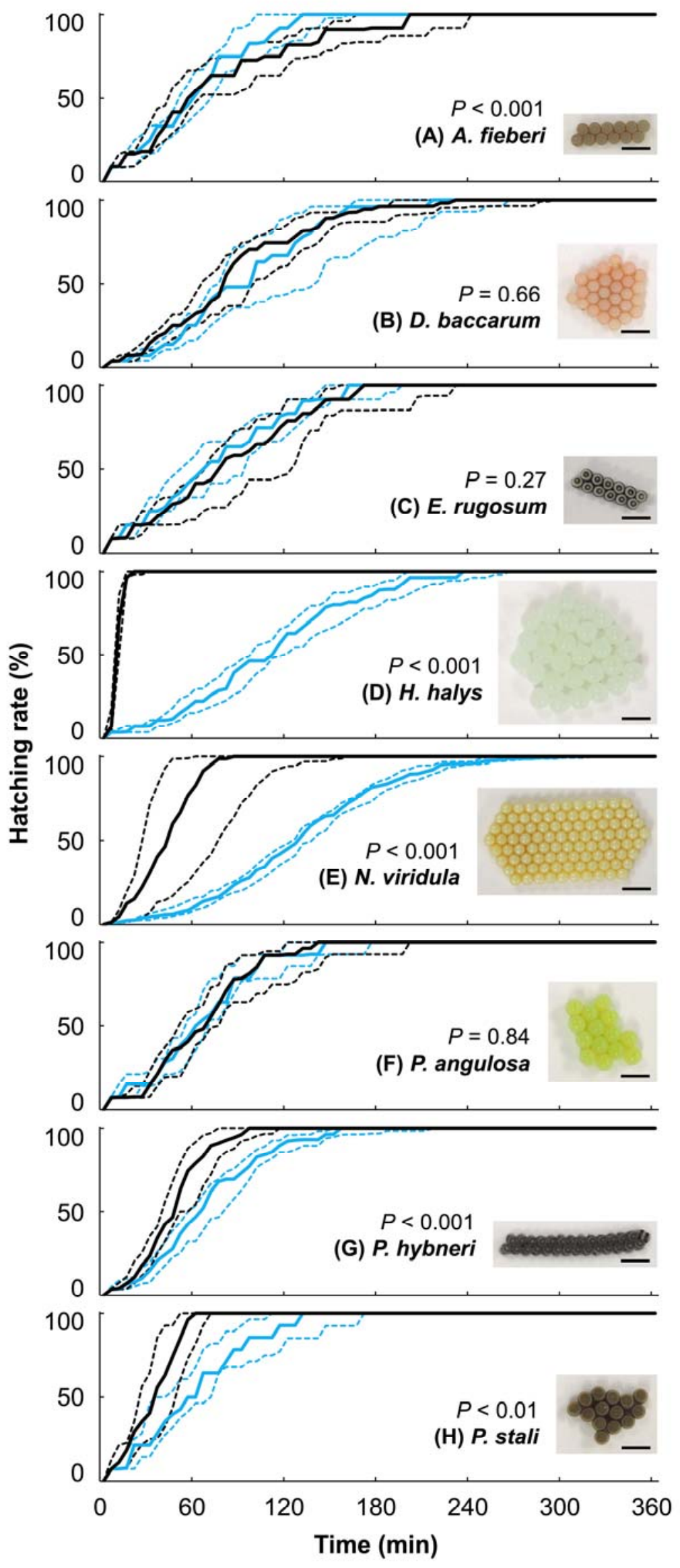
Fig. 1. Comparison of hatching patterns between intact egg clutches and eggs individually detached from egg clutches of eight species in Pentatomidae at $25^{\circ} \mathrm{C}$. (A) Aelia fieberi, (B) Dolycoris baccarum, (C) Eurydema rugosum (D) Halyomorpha halys, (E) Nezara viridula, (F) Palomena angulosa, (G) Piezodorus hybneri, and (H) Plautia stali. The median (solid line), the first quartile (lower dotted line), and the third quartile (upper dotted line) are shown for the hatching rate at $5 \mathrm{~min}$ intervals. $P$-values indicate statistical differences in hatching patterns between intact egg clutches and eggs individually detached from egg clutches (two-way repeated measures ANOVA with the Greenhouse-Geisser correction). Inset photographs show egg clutches of these species. Scale bar, $2 \mathrm{~mm}$. See Table 1 for further information on egg clutches used.
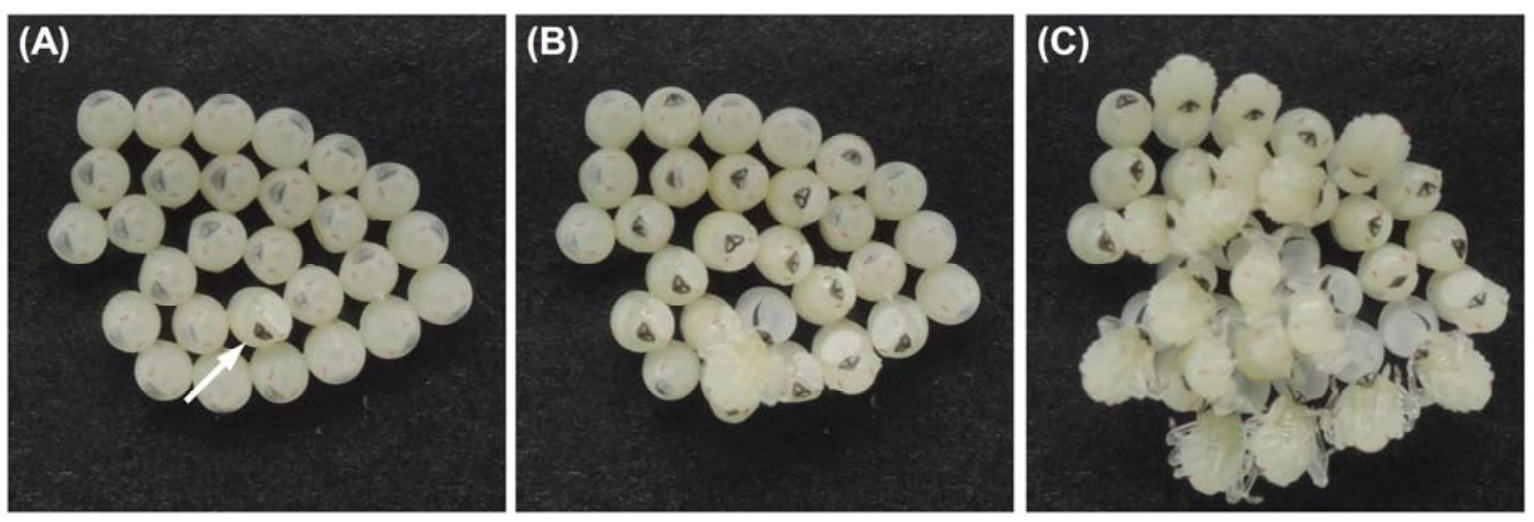

Fig. 2. Highly synchronized hatching in an intact egg clutch of Halyomorpha halys. (A) The first egg has just started to hatch (arrow). The egg buster (black triangle) and the compound eyes (red spots) can be seen in unhatched eggs. (B) After $5 \mathrm{~min}$, the whole body of the first nymph has emerged from the egg chorion and several other eggs have started to hatch. (C) After $10 \mathrm{~min}$, more than half of the nymphs have emerged from the egg chorions and the remaining eggs have also started to hatch. 